Plant Physiol. Biochem., 1998, 36 (1-2), 21-32

\title{
The Arabidopsis root as a model to study plant development
}

\author{
Ben Scheres and Harald Wolkenfelt \\ Department of Molecular Cell Biology, Padualaan 8, NL-3584 CH Utrecht, The Netherlands
}

\begin{abstract}
With its straightforward amenability to genetic approaches, Arabidopsis thaliana proves to be a powerful system to study biological processes in plants. The root of Arahidopsis has several additional features which make it a good model system to study developmental processes. It has a largely invariant ontogeny and fixed cellular organization. Continuous cellular differentiation in the root meristematic region allows monitoring of developmental processes after embryogenesis. The Arabidopsis root is also amenable for experimental manipulation. The simplicity of its organization allows large-scale mutant screens covering several aspects of root formation and growth. Experimental manipulations have uncovered the existence of positional cues important for pattern formation. Together with the several classes of mutants and the ongoing identification of genes these findings contribute to a better understanding of developmental processes at the cellular level. $\mathcal{C}$ Elsevier, Paris.
\end{abstract}

Key words Root, pattern formation, laser ablation, cell division, cell expansion, environment, Arabidopsis.

Abbreviations CLSM, confocal laser scanning microscope; GFP, green fluorescent protein; GUS, B-glucuronidase.

\section{Introduction}

It is beyond doubt that development is complex. Therefore, the use of model organisms that allow optimal experimental strategies is common practice among developmental biologists. A major criterion for selecting animal model systems like the fruit fly, the worm Caenorhabditis elegans, the mouse and the zebrafish has been the straightforward applicability of genetic analysis. Genetics (both "forward", starting from a mutant phenotype, and "reverse", starting from a known gene sequence) allows one to study development by interfering "from within" by mutation. This approach has proven to be powerful for the identification of genes involved in development. Once gene products are identified, biochemical and physiological studies can yield knowledge of the relevant molecular mechanisms. The relatively recent successes in the identification of gene products involved in development of Arabidopsis thaliana, Antirrhinum majus and Zea mays demonstrate that the study of plant development is heading in the same direction. A major role is played by genetic approaches at present, but these do not operate in isolation as they either prelude or go hand in hand with detailed physiological and biochemical studies.

It is, however, not only the applicability of genetics that determines the experimental ease with which processes can be studied in detail. The nematode $C$. elegans serves to illustrate that two other features of organisms are extremely useful for developmental analysis. Firstly, a constant cellular organization and cell lineage (relation between mother and daughter cells) enables one to identify cells by position and to accurately predict the destiny of any cell in a developing organism (Sulston and Horvitz, 1977). Secondly, transparency of developing structures allows physical manipulation of cells. Such an ability to interfere with development is of extreme importance in formulating or testing of hypotheses on cellular interactions. In C. elegans, the knowledge of cell lineage has facilitated the identification and analysis of mutant phenotypes (e.g. Horvitz and Sternberg, 1991). The transparency has been utilized to manipulate cells by reshuffling (e.g. Wood, 1991; Goldstein, 1992), by destruction of cells with a laser beam (e.g. Sulston and 
Horvitz, 1977), and by microinjection (e.g. Evans et al., 1994; Hunter and Kenyon, 1996).

Studies of the past five years have revealed that the Arabidopsis root has a for plants uncommonly constant cell lineage. Moreover, this organ is amenable to experimental analysis by virtue of its small size and transparency. Here, we review recent studies on Arabidopsis roots that exploit these features, often in combination with genetic screens for root mutants. This work has increased our understanding of pattern formation and control of cell proliferation in roots, but it also begins to address complex aspects of development which are specific to plants, such as cell expansion and response to the environment.

\section{Cells of the Arabidopsis root meristem have pre- dictable fates}

The mature part of the Arabidopsis root has an uncomplicated radial organization in which each of the cell layers can be readily recognized by their morphological characteristics. From outside to inside, conccntric layers of epidermis, cortical parenchyma ("cortex" hereafter) and endodermis with almost constant cell numbers encircle the stele tissue (fig. $1 \mathrm{~A}$ ). Within the stele, the pericycle encloses a simple diarch vascular system consisting of two phloem and two xylem poles (Dolan et al., 1993).

The meristem adds new cells to the mature part of the root, and the resulting regular cell files match and extend the earlier formed pattern of mature cells (fig. $1 \mathrm{~B}$ ). The basal-most cells of these cell files, termed initials, act as stem cells. They produce basal daughter cells that will remain initial-like and proximal daughters, which generate cells that differentiate upon displacement from the meristem. The sequence of cell division of the initials and their daughters is essentially invariant, which leads to a fixed contribution of the meristem cells to the different tissues (fig. $1 \mathrm{C}$ ).

The distal-most columella initial cells and the epidermal initials give rise to the root cap, of which the outer cells detach in time from the main root body. Due to the disappearance of the outer cap layers the initials remain at the same distance from the root apex. All initials surround a group of four non-dividing central cells termed the "quiescent centre" (Dolan et al., 1993). Under certain growth conditions these cells can be mitotically active to contribute to the cortical cell layer (Rost et al., 1996). The extent of violation of the lineage relationships depicted in figure $1 \mathrm{C}$ is investigated by genetically marking the progeny of single cells, and analysis of their contribution to tissues. Such a "clonal analysis" corroborates the notion of strict lineages in the Arabidopsis root (Dolan et al., 1994; Scheres et al., 1994). The predictability of the fate of individual cells in the Arabidopsis root greatly facilitates the interpretation of genetic and experimental analyses.

\section{The embryonic ontogeny of the Arabidopsis root is known}

The developing Arabidopsis embryo undergoes stereotyped cell divisions, which enables one to assess the contribution of embryonic cells to the different organ primordia (Mansfield and Briarty, 1991; Jürgens and Mayer, 1994). At the octant stage of embryogenesis in Arabidopsis, three domains can be defined (fig. 2). The apical domain forms the shoot apical meristem and the majority of the cotyledons, the central domain gives the hypocotyl and the majority of the root and the basal domain forms two cell types within

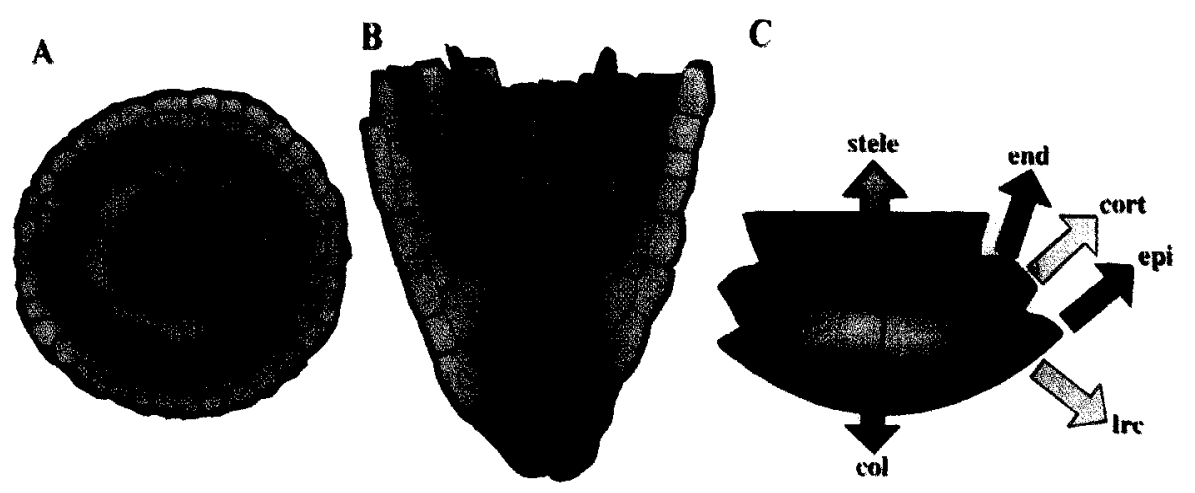

Figure 1. Schematic representation of tissues and cell types in the Arabidopsis root. A., transverse section. B, longitudinal scction. C, blow-up of initials surrounding quiescent centre (grey), arrows indicating direction in which initial cells add new cells to files. Note that cortical initials (green) and epidermal initials each give rise to two different cell types. 


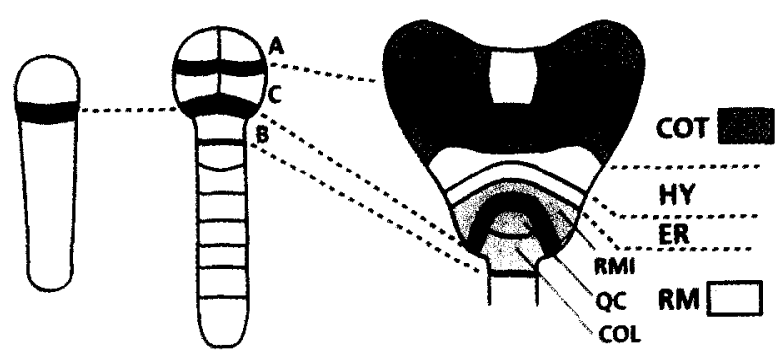

Figure 2. Fate map of the Arabidopsis embryo. Left to right: 1-cell, 8-cell and heart stage embryos. Bold lines: divisions separating apical (A), central (C) and basal (B) embryo regions (Jürgens, 1995). The basal embryo region is the hypophysis. Cell groups which give rise to seedling structures are indicated in the heart stage embryo. SAM, shoot apical meristem; COT, cotyledons; HY, hypocotyl; ER, embryonic root; RM, root meristem; RMI, root meristem initials; QC, quiescent centre; COL, columella root cap.

the distal region of the root the columella root cap and the quiescent center.

Analysis of the contribution of genetically marked embryonic cells to the root and hypocotyl has revealed that three lincage relationships are essentially invariant (Scheres et al., 1994). Firstly, the hypophysis, constituting the basal domain of the octant embryo, will give rise to the quiescent centre and the columella root cap only (fig. 2). Secondly, the separation of the protoderm, ground tissue and procambium is completed at the globular stage of embryogenesis, and these concentrically arranged layers invariantly give rise to epidermal- cortical- and stele tissues, respectively. A third constant relationship is that the cells which flank the hypophysis-derived cells at the late heart stage of embryogenesis become the root meristem initials (fig. 2).

The analysis of sectors has, however, also revealed variability in the contribution of embryonic regions to seedling structures. The hypocotyl/root boundary within the central domain, for example, only roughly coincides with a subdivision of the lower tier occurring at the early heart stage of embryogenesis. This subdivision is therefore not sufficient to separate cell fates. Border cells from either the upper or lower region are able to adopt the fate of the neighboring region, which indicates that the sharp boundary between root and hypocotyl is fixed at later stages of development. The root boundary is not an exceptional case of non-identity of embryo domains and organ primordia, as many cells derived from the central region contribute to the cotyledons (fig. 2). Such variable contributions reveal that the early subdivisions of the embryo do not segregate cell fates associated with the organ primordia.

In conclusion, root development during normal embryogenesis involves a rigid sequence of cell divisions and, with the exception of the root/hypocotyl boundary region, the origin of cells at a given developmental stage is known.

\section{Experimental manipulation: control of cell fate and cell differentiation}

In the nematode $C$. elegans, selected cells can be destroyed with a laser beam ("laser ablation"). Experiments relying on this technique have led to the discovery that, despite the rigid cell lineage, cell position was instrumental in determining the fate of many cells (e.g. Sulston and White, 1980). Living Arabidopsis roots, with their regular cell lineage relationships, can be imaged using confocal laser scanning microscopy (CLSM) (fig. 3). This has allowed the application of

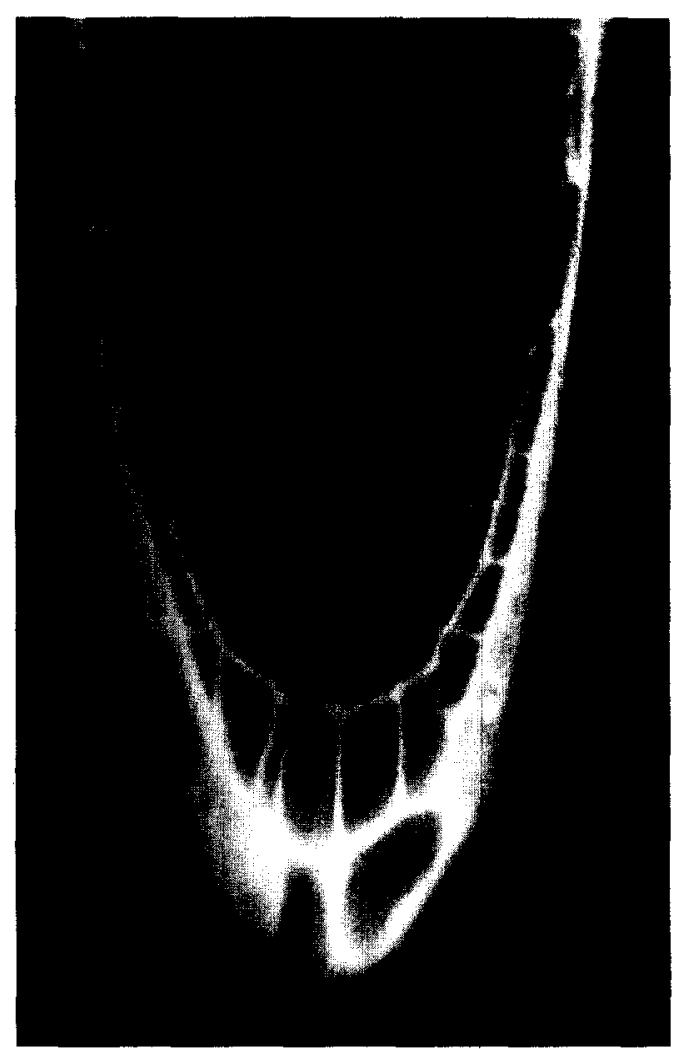

Figure 3. Confocal laser scan depicting the propidium iodine stained root tip of a living Arabidopsis seedling. The dye accumulates between cells and visualizes the cellular organization. Laser ablation is performed by parking the laser beam on a defined cell. Entry of the dye inside cells marks succesful ablation experiments. 
laser ablation to the study of root development. One major conclusion was that, like in $C$. elegans, position is of major importance in determining cell fate (van den Berg et al., 1995).

In plants, cell lineage is generally variable. For example, plasticity of shoot meristem development is evident from sector analysis and from surgical experiments (Poethig, 1987; Steeves and Sussex, 1989). The predictable cell fates in the Arabidopsis root therefore do not appear to arise from an exceptional mechanism of development, but rather they reflect precise cell division sequences that conserve the spatial organization of cells. Taken together, the root meristem provides us with a unique combination of a nearly constant cell lineage, facilitating the analysis of experiments, and the flexible position-dependent mode of development that is considered the hallmark of plant development.

Laser ablation experiments have also demonstrated that cortex initial cells perform the appropriate asym metric divisions giving rise to cortex and endodermis only when in contact with more mature cells within the cortical cell layer. This has led to the suggestion that positional information in the root meristem is provided by "top-down signaling": more mature cells act as a template to guide cell fate of the root meristem initials (van den Berg et al., 1995). The molecular nature of the signals involved is so far unknown. Elegant experiments on embryos of the brown alga Fucus spiralis have created some precedence for a role of the cell wall in signaling cell fate (Berger et al., 1994). On the other hand, studies on the distribution and conductance of plasmodesmata in the Arabidopsis root tip reveal predominant plasmodesmatal connections within cells of the same tissue layers, which would be in line with cytoplasmic transmission of positional information (Zhu, T., Lucas, W. J. and Rost, T., personal communication). Arabidopsis roots can be micro-injected, and such experiments have demonstrated cytoplasmic isolation of fully differentiated cells (Duckett $e t$ al., 1994). This observation suggests that cytoplasmic connections may transmit positional information only in the meristematic region where cells are not yet completely differentiated.

The mechanism by which the meristem retains undifferentiated cells has also been studied in the Arabidopsis root. Ablation of quiescent centre cells has revealed that they inhibit differentiation of the columella and most likely all initial cells. They do so through signals which act at the single-cell range and are possibly contact-dependent (our unpublished data).

In conclusion, the ability to destroy single cells in the Arabidopsis root meristern has provided us with evidence for positional information guiding cell fate, with a model on how this information is transmitted, and with evidence for signals, emanating from the quiescent centre, which control cell differentiation.

\section{Landmarks allow identification of developmental mutants}

The developmental systems in which genetic analysis has been successfully applied all possess easily distinguishable markers ("landmarks") for development. The larval denticle belts, which are characteristic for each segment in fruit flies, form a classical example of conspicuous traits aiding in the identification of developmentally relevant genes (Nüsslein-Volhard and Wieschaus, 1980). The dependence on landmarks is also evident when one considers the area of major progress in plant development: the easily distinguished floral organs with their many distinct features have enabled the identification of many relevant floral mutants (Weigel and Meyerowitz, 1994).

Despite its structural simplicity, the Arabidopsis root contains many recognizable markers which can be utilized for genetic screens (Benfey and Schiefelbein, 1994). However, these landmarks are not always easily scored under the dissecting microscope which is the method of choice in most large-scale genetic screens for developmental mutants. Root hair morphology, root cell elongation, and root meristem activity have been useful traits to isolate specific mutants (see below), but hitherto the identification of pattern mutants has been somewhat indirect. Mutants with radial as well as apical-basal pattern defects have been mainly pre-selected by a secondary criterion: root growth (Benfey et al., 1993; Scheres et al., 1995; our unpublished data). This is a biased way of pre-screening, which presupposes that a growth defect accompanies the primary defect. Consequently, patterning mutants with normal growth and embryonic lethal pattern mutants will be missed. Indirect pre-screening can be avoided in future by two different approaches. Firstly, once a small set of genes is identified which is specifically involved in a particular developmental pathway, enhancer or suppressor screens may allow further analysis of this pathway. Secondly, transgenic lines with marker genes that highlight a particular cell type or region in the developing organism, facilitates 


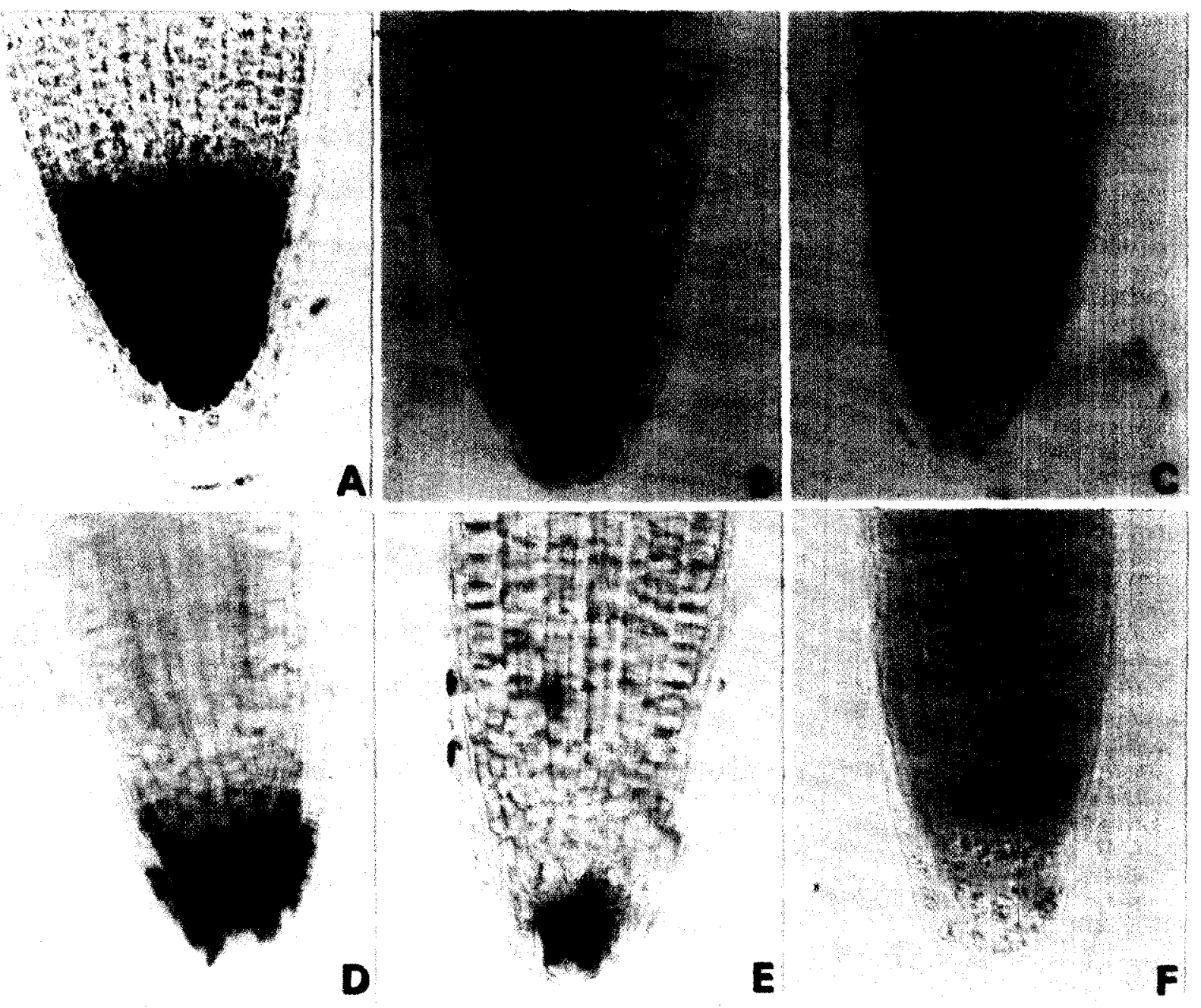

Figure 4. X-Gluc stained roots from transgenic Arabidopsis containing $\beta$-glucuronidase (GUS) fusions which mark specific regions in the root tip. A, complete root cap marked by 35S-B2::GUS fusion (Benfey et al., 1990). B, columella root cap marked by promoter trap pMOG533-1027 (Goddijn et al., 1993). C, lateral root cap marked by enhancer trap LRC244 (Malamy and Benfey, 1997). D, outer layers of complete root cap marked by pMOG533-649. E, outer layer of columella root cap marked by pMOG533-174. F, quiescent centre and surrounding intials marked by pMOG533-124.

the identification of less obvious phenotypes. Such transgenic lines are now available (fig. 4; Malamy and Benfey, 1997; Topping and Lindsey, 1997; our unpublished data). The combination of enhancer trap constructs with selectable transposition allows large-scale isolation of lines with relevant expression patterns (Sundaresan et al., 1995). Currently available promoter and enhancer trap lines can be used for mutagenesis experiments to identify genes involved in setting up specific expression patterns. Especially promising for this purpose are recently described enhancer traps based on Green Fluorescent Protein
(GFP) fusions (Haseloff et al., 1997). The GFP protein can be visualized directly in living roots, without adding toxic chemicals.

\section{Genetic analysis}

Over the past years, the Arabidopsis root has been the subject of a number of genetic studies aimed at defining genes involved in a large variety of processes (tab. 1). Below we will briefly highlight a selection of the identified mutants/genes, grouped into four broad functional categories: pattern formation, cell division, cell expansion and environmental responses. Our 
Table 1. Arabidopsis genes and the phenotype they display in roots.

\begin{tabular}{|c|c|c|}
\hline Gene & Phenotype & References \\
\hline \multicolumn{3}{|l|}{ Pattern formation } \\
\hline MONOPTEROS & aberrant axialization of provascular tissue & Berleth and Jürgens, 1993 \\
\hline$M O ̈ W E$ & reduced hypocotyl, missing root & Berleth et al., 1996 \\
\hline BASAL DELETION & reduced hypocotyl, missing root & Berleth et al., 1996 \\
\hline$H O B B I T$ & no root meristem & Scheres et al., 1996 \\
\hline$B O M B A D I L$ & reduced hypocotyl, missing root & Scheres et al., 1996 \\
\hline$O R C$ & defective root meristem & Scheres et al., 1996 \\
\hline GREMLIN & defective root meristem & Scheres et al., 1996 \\
\hline PIPPIN & defective root meristem & Scheres et al., 1996 \\
\hline ABERRANT LATERAL & no lateral primordia & Celenza et al., 1996 \\
\hline \multicolumn{3}{|l|}{ ROOT FORMATION4 } \\
\hline SHORT ROOT & no endodermis & Benfey et al., 1996; Scheres et al., 1995 \\
\hline PINOCCHIO & no cortex & Scheres et al., 1995 \\
\hline SCARECROW & no segregation of endodermal/cortex fates & Scheres et al., 1995; Malamy and Benfey, 1997 \\
\hline WOODEN LEG & too few vascular cells & Scheres et al. 1995 \\
\hline GOLLUM & atypical vascular organisation & Scheres et al., 1995 \\
\hline TRANSPARANT TESTA GLABRA & ectopic root hairs & Galway et al., 1994 \\
\hline GLABRA2 & ectopic root hairs & Masucci et al., 1996 \\
\hline CONSTITUTIVE & ectopic root hairs, short root/defective & Kieber et al., 1993 \\
\hline \multicolumn{3}{|l|}{ TRIPLE RESPONSI } \\
\hline $\begin{array}{l}\text { ECTOPIC ROOT HAIR } 1-3 \\
(\text { ERH } 2=\text { POM } 1)\end{array}$ & downegulation of ethylene & Schneider et al., 1997 \\
\hline ROOT HAIRLESS $1-3$ & root hairless & Schneider et al., 1997 \\
\hline \multicolumn{3}{|l|}{ Meristem activity } \\
\hline ROOT MERISTEMLESS 1,2 & no post-embryonic root meristem activity & Cheng et al., 1995 \\
\hline STUMP & no post-embryonic root meristem activity & Berleth et al., 1996 \\
\hline ABERRANT LATERAL & no continued root meristem activity & Celenza et al., 1995 \\
\hline ROOT FORMATION3 & & \\
\hline CYCIAT & & Hemerly et al., 1992 \\
\hline$C D C 2 a$ & & Ferreira et al., 1991 \\
\hline$C D C .2 b$ & & Imajuku et al., 1992 \\
\hline SUPERROOT & elevated auxin levels & Boerjan et al., 1995 \\
\hline \multicolumn{3}{|l|}{ Cell expansion } \\
\hline ROOT HAIR DEFECTIVE3 & no cell expansion & $\begin{array}{l}\text { Schiefelbein and Sommerville, 1990; } \\
\text { Wang et al., } 1997\end{array}$ \\
\hline DIMINLITO & no cell expansion & Takahashi et al., 1995 \\
\hline LION'S TALL & no cell expansion & Benfey et al., 1993; Hauser et al., 1995 \\
\hline STUNTED PLANTI & cells in elongation zone fail to elongate & Baskin et al., 1995 \\
\hline$C O B R A$ & abnormal cell elongation & Benfey et al., 1993; Hauser et al., 1995 \\
\hline CUIL & deregulated expansion, epidermal & Hauser et al., 1995 \\
\hline CUDGE & deregulated expansion, epidermal & Hauser et al., 1995 \\
\hline POM-POMI & deregulated expansion & Hauser et al., 1995 \\
\hline POM-POM2 & deregulated expansion & Hauser et al., 1995 \\
\hline$S A B R E$ & abnormal cortical cell expansion & $\begin{array}{l}\text { Benfey et al., 1993; Aeschbacher et al., 1995: } \\
\text { Hauser et al., } 1995\end{array}$ \\
\hline EPIDERMAL BLEBBING & blebbing of outer epidermal cell wall & Baskin et al., 1992 \\
\hline RADIALLY SWOLLENI-3 & fat roots & Baskin et al., 1992 \\
\hline ROOT HAIR DEFECTIVE6 & defective root hair initiation & Masucci and Schiefelbein, 1994 \\
\hline ROOT HAIR DEFECTIVE 1,2,4 & defective root hair enlargement & Schiefelbein and Sommerville, 1990 \\
\hline$I I P I$ & abnormal root hair tip growth & Schiefelbein et al., 1993 \\
\hline LONG HYPOCOTYL3 & long root hairs when grown in light & Reed et al., 1993 \\
\hline \multicolumn{3}{|l|}{ Response to the environment } \\
\hline WAVl & no root tip rotation & Okada and Shimura, 1990 \\
\hline WAV 2,3 & high rate of root tip rotation & Okada and Shimura, 1990 \\
\hline WAV4 & $\begin{array}{l}\text { irregular timing of reversion of root } \\
\text { tip rotation }\end{array}$ & Okada and Shimura, 1990 \\
\hline
\end{tabular}


Table 1. Arabidopsis genes and the phenotype they display in roots.

\begin{tabular}{lll}
\hline Gene & Phenotype & References \\
\hline REDUCED ROOT GRAVITOPISMI & reduced response to gravity & Simmons et al., 1995 \\
AGRl=WAV6 & reduced response to gravity & Bell and Maher, 1990; Okada and Shimura, 1990 \\
AUXI=WAV5 & no response to gravity & Maher and Martindale, 1990; \\
& & Okada and Shimura, 1990 \\
AXR4 & no response to gravity & Hobbie and Estelle, 1995 \\
$S K U l, 2$ & exaggerated right-slanting growth & Rutherford and Masson, 1996 \\
\hline
\end{tabular}

selection primarily serves to illustrate the four categories without aiming to be complete.

\section{Pattern formation}

During the process of pattern formation, positional information is interpreted to give rise to a specific spatial arrangement of differentiated tissues/cells. Mutants with disrupted cell or tissue patterns can be used to identify genes involved in the interpretation process itself, or in the resulting establishment of cell or tissue identity. Several recessive mutants which are defective in patterning of the Arabidopsis root have been identified ( $t a b .1)$. Here, we will restrict discussion to those that are characterized in some detail.

Two genes have been identified which are essential for the embryonic specification of the root primordium. Seedlings homozygous for mutant alleles of the MONOPTEROS (MP) gene lack both the root and the hypocotyl (Berleth and Jürgens, 1993). Comparison of the embryonic and post-embryonic phenotypes led to the suggestion that the $M P$ gene may be primarily required for specific aspects of vascular cell development (Przemeck et al., 1996). The MP gene has been cloned and its expression pattern is consistent with this hypothesis (Hardtke, C. and Berleth, T., personal communication). The dramatic effect of $m p$ mutants on root and hypocotyl development during embryogenesis remains a strong indication for the importance of interactions between the central and basal embryo domains for proper pattern formation (Berleth and Jürgens, 1993; fig. 2).

hobbit Mutants lack the specification of both parts of the root cap, have no recognizable quiescent centre, and lack root meristem activity (Scheres et al., 1996). The earliest reported phenotype in hobbit mutants is aberrant development of the hypophyseal cell region. At later stages of embryogenesis, the adjoining region of the root is not correctly specified. Therefore, the $H O B B I T$ gene appears to be primarily required for the specification of the basal domain (fig. 2), which in turn is required for the specification of the adjoining root meristem region.

In the radial dimension, several mutants with altered tissue layers have been identified ( $t a h .1)$. The mutants all display an embryo phenotype, corroborating the notion that the radial tissue pattern in the seedling is set up during embryogenesis (Scheres et al., 1995). The shortroot mutant lacks the endodermal cell layer and the second cortical cell layer in the hypocotyl (Benfey et al., 1993; Scheres et al., 1995). The SHORTROOT gene therefore appears to be necessary for controlling the number of cell layers in the cortical tissue as well as for endodermal cell fate. scarecrow Mutants display a very interesting and uncommon phenotype: one layer of ground meristem is missing and the remaining cell layer in the root has features of both cortex and endodermis (Scheres et al., 1995; Di Laurenzio et al., 1996). It has been concluded that the SCARECROW gene, which encodes a putative transcription factor, is involved in the execution of specific asymmetric cell divisions (Di Laurenzio et al., 1996).

The circumferential pattern of alternating hair-bearing (trichoblast) and hairless (atrichoblast) epidermal cells is a conspicuous trait that has allowed the identification of many mutants (tab. 1). The transparant testa glabra (ttg) and glabra2 ( $\mathrm{gl} 2)$ mutants produce ectopic root hairs. Therefore the atrichoblast cell fate requires the TTG and GL2 genes, which are also necessary for shoot epidermal patterning (Galway et al., 1994; Masucci et al., 1996). In the latter case they promote hair-bearing (trichome) epidermal cell fate. The $G L 2$ gene contains a homeodomain sequence (Rerie $e t$ $a l ., 1994$ ) and $t$ tg mutants can be complemented by the maize transcription factor $R$ (Lloyd et al., 1992). In addition to the emerging transcription factor module for atrichoblast specification, the ROOT HAIRLESS genes may be involved in specification of trichoblast cell fate (Schneider et al., 1997). Genetic and experimental studies on epidermal cell patterning have revealed roles for the phytohormones auxin and ethylene in root hair cell specification (tab. 1; Dolan et al., 
1994; Masucci and Schiefelbein, 1994, 1996; Tanimoto et al., 1995). The role of ethylene in the initiation of root hair formation may be permissive, but the differential sensitivity to ethylene of epidermal cell files in $t$ tg and $g l 2$ mutants points to an additional, instructive role for the ethylene signaling pathway in patterning the epidermis (Cao, X. F. and Dolan, L., personal communication).

The majority of patterning mutants show the same phenotype in the primary root formed in the embryo, and in secondary roots that are formed post-embryonically (Scheres et al., 1995; 1996). This implies that many embryonic patterning genes are recruited again during secondary root formation.

\section{Meristem activity}

The ability to undergo continuous cell division is one of the defining characteristics of the root meristem. As discussed above, a mitotically active root meristem is absent in seedlings homozygous for mutant alleles of the MONOPTEROS and HOBBIT genes. However, these genes are required early, and they presumably affect cell division in the root meristem indirectly via a chain of intermediate events. Mutants with more specific defects are required for genetic analysis of mitotic control in the root meristem. The exact knowledge of cell pattern and cell numbers in the mature embryo have allowed the selection of mutants with a correctly patterned root apex, but with defects in the onset of post-embryonic divisions (tab. 1; Cheng et al., 1995; Berleth et al., 1996; our unpublished data). The identified mutants may pinpoint genes that are specifically involved in triggering and maintaining cell divisions in the meristem, although it still remains possible that physiological defects cause the mutant phenotypes.

Control of the onset and maintenance of the cell cycle is also relevant for the formation of secondary roots. New lateral root primordia originate from cells in the pericycle layer, which become mitotically activated after a period of cell cycle arrest. Classical studies have demonstrated a link between the phytohormone auxin and lateral root formation (Torrey, 1950). Lateral root mutants have confirmed this link to auxin, and these mutants may serve as an entrance for studying the mechanisms involved in lateral root formation (Boerjan et al., 1995; Celenza et al., 1995).

Cell division in Arabidopsis has also been studied by the isolation of genes homologous to two yeast cell cycle regulator families, the cyclin-dependent kinases and the cyclins (Ferreira et al., 1991; Hemerly et al., 1992; Imajuku et al., 1992). Expression of the CDC2a gene marks cells which are competent for cell division (Hemerly et al., 1993), and overexpression accelerates cell division. Expression of a dominant negative CDC2a was lethal in Arabidopsis and inhibited cell division rate in tobacco (Hemerly et al., 1995). Interestingly, these tobacco plants had larger cells but no altered cell morphology. In contrast, overexpression of the CYCIAT gene has been reported to lead to an increase in root growth (Doerner et al., 1996). More research is needed to explain these apparently contradictory effects of cell cycle gene expression on root growth.

\section{Cell expansion}

Plant cell expansion involves cell wall changes which allow osmotically based turgor pressure to drive cell enlargement (Cosgrove, 1993). The direction and ratc of cell expansion is a major factor in morphogencsis as it determines not only the shape of the cell but also that of the organism (whether or not feedback mechanisms occur at the organism level). Despite many studies on the role of phytohormones, cytoskeletal proteins and cell wall loosening enzymes, the molecular mechanisms underlying cell elongation are not well understood. The Arabidopsis root undergoes well-described expansion in the elongation zone as well as during root hair formation, which has allowed genetic studies on cell expansion. Mutants with deregulated cell expansion representing many different genes have been identified (Schiefelbein and Somerville, 1990; Baskin et al., 1992; Benfey et al., 1993; Hauser et al., 1995). Together, these mutants suggest complex, often tissue-specific controls on cell elongation. In the case of sabre mutants, interactions with phytohormones were observed and it was proposed that the SABRE gene product counteracted ethylenedependent radial cell expansion (Aeschbacher et al., 1995). It is of interest that root expansion mutants can be either defective in the extent or the orientation of expansion or in both (Hauser et al., 1995), which implies that cell expansion is under extensive genetic regulation. In many cases, the effect on cell elongation of the mutants is not restricted to the root. For example, screens for hypocotyl elongation mutants have identified the procuste mutants, which turned out to bc allelic to the cuil root expansion mutant (Höfte, $\mathrm{H}$., personal communication). In conclusion, root expansion mutants provide entrances to the regulation of cell 
morphology at multiple levels, and the identified genes may act either in a global or organ- and tissue-specific manner. Integration of genetic and physiological approaches may help to unravel the complex control of cell expansion as a necessary step towards the understanding of plant morphogenesis.

It is clear that cell expansion and the role of the cell wall does not relate directly to well-studied examples of animal development. Nevertheless, the identification of genes involved in this process may provide links to other organisms, aiding to the understanding of gene function. An example is provided by the recent molecular characterization of the ROOT HAIR DEFECTIVE3 (RHD3) gene, which shared homology with a number of genes in unrelated organisms (Wang et al., 1997). In our vicw, an advantage in studying cell expansion of Arabidopsis will be the possibility to link cell-specific factors involved in the determination of cell shape to the genes that specify their expression during pattern formation.

\section{Response to the environment}

An extremely important aspect of plant development is its capacity to integrate and respond to information from the environment. Since some of the agents capable of modulating these responses, such as phytohormones, have been long known, this aspect has received considerable attention. The first clues are now being obtained on how phytohormones can combine with genetic programs to orchestrate developmental plasticity. Genetic analysis of environmental responses has been used particularly successful in the fields of lightperception and control of flowering time, but has also been applied in the root field. Roots orient their growth by responding to a number of environmental stimuli (Okada and Shimura, 1992). Due to the ease with which the orientation of root growth can be monitored, the perception of gravity, light and touch stimuli in Arabidopsis roots has been amenable to genetic analysis (tab. 1). Gravitropic mutants have been isolated using response assays and by screening for mutants with impaired sensitivity to exogenously applied auxin (Masson, 1995; Estelle, 1996). The $A U X 1$ gene, of which mutant alleles have been identified in both types of screens, has recently been cloned and the encoded protein is similar to amino acid transporters (Bennett et al., 1996). This suggests that $A U X 1$ may act as an auxin transporter, which substantiates a long-proposed link between auxin transport and gravitropism. A screen based on the waving patterns of roots on tilted agar plates resulted in the isolation of mutants with altered response to gravity, to a lateral light source and to gravity-induced touch (Okada and Shimura, 1992). It is of considerable interest that the different mutants apparently define genes involved in responses specific to one stimulus, as well as genes involved in response to several of the stimuli. This implies common as well as specific branches of the signal transduction pathways involved, and hints to a complexity that cannot yet be fully grasped.

It is interesting to note that the response of plant development to the environment can be likened to animal behavior. Consequently, substantial analogies exist between genetic screens utilizing behavior to isolate developmental mutants in animals, such as screens to identify photoreceptor cell identity mutants in the fruit fly, and gravitropic mutant screens in roots. Rather then providing detailed experimental guiding, such a comparison may serve to trigger ideas which need to be worked out in a species-specific context.

\section{Concluding remarks}

The uncomplicated structure and the largely invariant cell lineage of the Arabidopsis root have enabled both experimental manipulation and the identification of genes involved in two aspects of root development: paltern formation and cell cycle regulation. It is noteworthy that the advantages of the root system have been exploited by methods analogous to those used in animal models, like the worm C. elegans. As a result, it is now evident that cells in the Arabidopsis root meristem are confronted with positional information. The utilization of positional information appears to be a common theme in plant development. Genes identified so far that are involved in reading out or translating positional information are first active during embryogenesis, but they are also involved in patterning lateral roots. Furthermore, both genetic and molecular approaches are providing the first insights into the regulation of the cell cycle during root development. It can be foreseen that molecular landmarks will greatly enhance the possibility to identify genes involved in these processes.

Since the shape of a plant cell is intimately linked to its cell wall, the $C$. elegans analogy is less useful when the morphogenetic aspect of root development is taken into consideration. Nevertheless, the identification of many cell expansion mutants hint that the complex 
processes of morphogenesis at the cellular and organism levels are now amenable to genetic analysis.

Last but not least, Arabidopsis roots have proven to be powerful tools to identify genes involved in the response to various environmental stimuli. Here, parallels can be noted between plant and animal research on a completely different level, the design of "behavioral screens".

The challenge that lies ahead now is to understand the genetic programmes that determine cell fate, cell shape and cell division status in a single organ, and how these programmes interact. A second step is to combine these insights with knowledge on how these programmes can be modulated by various stimuli. It is only then that we may hope to truly understand how plant organs develop with such remarkable plasticity.

Acknowledgements. We thank Dick Smit for preparing the drawings, Thomas Berleth and Peter Weisbeek for useful comments on the manuscript, and Phil Benfey, Jocelyn Malamy and Peter Sijmons for providing marker lines used in figure 4 . We apologize to our colleagues in the root field whose work was not appropriately cited due to space limitations.

(Received July 15, 1997; accepted August 1st, 1997)

\section{References}

Aeschbacher R. A., Hauser M.-T., Feldmann K. A. and Benfey P. N., 1995. The SABRE gene is required for normal cell expansion in Arabidopsis. Genes Dev., 9, 330340.

Baskin T. I., Betzner A. S., Hoggart R., Cork A. and Williamson R. E., 1992. Root morphology mutants in Arabidopsis thaliana. Aust. J. Plant Physiol., 19, 427-437.

Baskin T. I., Cork A., Williamson R. E. and Gorst R., 1995. STUNTED PLANT1, a gene required for expansion in rapidly elongating but not in dividing cells and mediating root growth responses to applied cytokinin. Plant Physiol., 107, 233-243.

Bell C. J. and Maher E. P., 1990. Mutants of Arabidopsis thaliana with abnormal gravitropic responses. Mol. Gen. Genet., 220, 289-293.

Benfey P. N. and Schiefelbein J. W., 1994. Getting to the root of plant development: the genetics of Arabidopsis root formation. $T I G, \mathbf{1 0}, 84-88$.

Benfey P., Ren L. and Chua N.-H., 1990. Combinatorial and synergistic properties of CaMV $35 \mathrm{~S}$ enhancer subdomains. EMBO J., 9, 1685-1696.

Benfey P., Linstead P., Roberts K., Schiefelbein J., Hauser M.-T. and Aeschbacher R., 1993. Root development in Arabidopsis: four mutants with dramatically altered root morphogenesis. Development, 119, 57-70.
Bennet M. J., Marchant A., Green H. G., May S. T., Ward S. P., Millner P. A., Walker A. R., Schulz B. and Feldmann K. A., 1996. Arabidopsis AUXl gene: a permease-like regulator of root gravitropism. Science, 273, 948-950.

Berger F., Taylor A. and Brownlee C., 1994. Cell fate determination by the cell wall in early Fucus development. Science, 263, 1421-1423.

Berleth T. and Jürgens G., 1993. The role of the monopteros gene in organising the basal body regions of the Arabidopsis embryo. Development, 118, 575-587.

Berleth T., Hardtke C. S., Przemeck G. K. H. and Müller J., 1996. Mutational analysis of root initiation in the Arabidopsis embryo. Plant Soil, 187, 1-9.

Boerjan W., Cervera M.-T., Delarue M., Beeckman T., Dewitte W., Bellini C., Caboche M., Van Onckelen H., Van Montagu M. and Inzé D., 1995. superroot, a recessive mutation in Arabidopsis confers auxin overproduction. Plant Cell, 7, 1405-1419.

Celenza J. Jr., Grifasi P. and Fink G., 1995. A pathway for lateral root formation in Arabidopsis thaliana. Genes Dev., 9, 2131-2142.

Cheng J.-C., Sweely K. A. and Sung Z. R., 1995. RML1 and RML2, Arabidopsis genes required for cell proliferation at the root tip. Plant Physiol., 107, 365-376.

Cosgrove D., 1993. How do plant cell walls extend? Plant Physiol., 102, 1-6.

Di Laurenzio L., Wysocka-Diller J., Malamy J. E., Pysh L., Helariutta Y., Freshour G., Hahn M. G., Feldmann K. E., Benfey P. N., 1996. The SCARECROW gene regulates an asymmetric cell division that is essential for generating the radial organization of the Arabidopsis root. Cell, 86, 423-433.

Doerner P., Jørgensen J.-E., You R., Steppuhn J. and Lamb C., 1996. Control of root growth and development by cyclin expression. Nature, $\mathbf{3 8 0}, 520-523$.

Dolan L., Janmaat K., Willemsen V., Linstead P., Poethig S., Roberts K. and Scheres B., 1993. Cellular organisation of the Arabidopsis root. Development, 119, 71-84.

Dolan L., Duckett C. M., Grierson C., Linstead P., Schneider K., Lawson E., Dean C., Poethig S. and Roberts K., 1994. Clonal relationships and cell patterning in the root epidermis of Arabidopsis. Development, 120, 2465-2474.

Duckett C., Oparka K., Prior D., Dolan L. and Roberts K., 1994. Dye-coupling in the root epidermis of Arabidopsis is progressively reduced during development. Development, 120, 3247-3255.

Estelle M., 1996. Plant tropisms: The ins and outs of auxin.. 1996. Curr. Biol., 6, 1589-1591.

Evans T., Crittenden S., Kodoyianni V. and Kimble J., 1994. Translational control of maternal $g l p-1$ mRNA establishes an asymmetry in the Caenorhabditis elegans embryo. Cell, 77, 183-194.

Ferreira P. C. G., Hemerly A. S., Villaroel R., Van Montagu M. and Inzé D., 1991. The Arabidopsis functional homolog of the $\mathrm{p} 34^{\mathrm{cdc} 2}$ protein kinase. Plant Cell, 3, 531540 . 
Galway M. E., Masucci J. D., Lloyd A. M., Walbot V., Davis R. W. and Schiefelbein J. W., 1994. The TTG gene is required to specify epidermal cell fate and cell patterning in the Arabidopsis root. Dev. Biol., 166, 740-754.

Goddijn O. J. M., Lindsey K., van der Lee F. M., Klap J. C. and Sijmons P. C., 1993. Differential gene expression in nematode-induced feeding structures of transgenic plants harbouring promoter-gusA fusion constructs. Plant J., 4, 863-873.

Goldstein B., 1992. Induction of gut in Caenorhabditis elegans embryos. Nature, 357, 255-257.

Haseloff J., Siemering K. R., Prasher D. and Hodge S., 1997. Removal of a cryptic intron and subcellular localisation of green fluorescent protein are required to mark transgenic Arabidopsis plants brightly. Proc. Natl. Acad. Sci. USA, 94, 2122-2127.

Hauser M.-T., Morikami A. and Benfey P. N., 1995. Conditional root cxpansion mutants of Arabidopsis. Development, 121, 1237-1252.

Hemerly A., Bergounioux C., Van Montagu M., Inzé D. and Ferreira P., 1992. Genes regulating the plant cell cycle: isolation of a mitotic-like cyclin from Arabidopsis thaliana. Proc. Natl. Acad. Sci. USA, 89, 3295-3299.

Hemerly A. S., Ferreira P. C. G., de Almeida Engler J., Van Montagu M., Engler G. and Inz( D., 1993. $C d c 2 a$ expression in Arabidopsis thaliana is linked with competence for cell division. Plant Cell, 5, 1711-1723.

Hemerly A., de Almeida Engler J., Bergounioux C., Van Montagu M., Engler G., Inzé D. and Ferreira P., 1995. Dominant negative mutants of the cdc2 kinase uncouple cell division from iterative plant development. $E M B O \mathrm{~J}$., 14, 3925-3936.

Hobbie L. and Estelle M., 1995. The axr4 auxin-resistant mutants of Arabidopsis thaliana define a gene important for root gravitropism and lateral root initiation: Plant J., 7, $211-220$.

Horvitz H. R. and Sternberg P. W., 1991. Multiple intercellular signalling systems control the development of the Caenorhabditis elegans vulva. Nature, 351, 535-541.

Hunter C. and Kenyon C., 1996. Spatial and temporal controls target pal- 1 blastomere specification activity to a single blastomere lineage in Caenorhabditis elegans embryos. Cell, 87, 217-226.

Imajuku Y., Hirayama T., Endoh H. and Oka A., 1992. Exon-intron organization of the Arabidopsis thaliana protein kinase genes $C D C 2 a$ and $C D C 2 b$. FEBS Lett., 304, 73-77.

Jürgens G., 1995. Axis formation in plant embryogenesis: cues and clues. Cell, 81, 467-470.

Jürgens G. and Mayer U., 1994. Arabidopsis. In EMBRYOS. Colour atlas of development, Bard J., ed., Wolfe publications, London, 7-21.

Kieber J. J., Rothenberg M., Roman G., Feldmann K. A. and Ecker J.R., 1993. CTRl, negative regulator of the ethylene response pathway in Arabidopsis encodes a member of the Raf family of protein kinases. Cell, $\mathbf{7 2}$, $427-441$.
Lloyd A. M., Walbot V. and Davis R. W., 1992. Arabidopsis and Nicotiana anthocyanin production activated by maize regulators $R$ and $C l$. Science, 258, 1773-1775.

Maher E. P. and Martindale S. J. B., 1990. Mutants of Arabidopsis thaliana with altered responses to auxins and gravity. Biochem. Genet., 18, 1041-1053.

Malamy J. E. and Benfey P. N., 1997. Organisation and cell differentiation in lateral roots of Arabidopsis thaliana. Development, 124, 33-44.

Mansfield S. and Briarty L., 1991. Early embryogenesis in Arabidopsis thaliana. II. The developing embryo. Can.J. Bot., 69, 461-467.

Masson P. H., 1995. Root gravitropism. BioEssays, 17, 119127.

Masucci J. D. and Schiefelbein J. W., 1994. The rhd6 mutation of Arabidopsis thaliana alters root-hair initiation through an auxin- and ethylene-associated process. Plant Physiol., 106, 1335-1346.

Masucci J. D. and Schiefelbein J. W., 1996. Hormones act downstream of $T T G$ and $G L 2$ to promote root hair outgrowth during epidermis development in the Arabidopsis root. Plant Cell, 5, 1505-1517.

Masucci J. D., Rerie W. G., Foreman D. R., Zhang M., Galway M. E., Marks M. D. and Schiefelbein J. W., 1996. The homeobox gene GLABRA 2 is required for position-dependent cell differentiation in the root epidermis of Arabidopsis thaliana. Development, 122, 12531260.

Nüsslein-Volhard C. and Wieschaus E., 1980. Mutations affecting segment number and polarity in Drosophila. Nature, 287, 795-801.

Okada K. and Shimura Y., 1990. Reversible root tip rotation in Arabidopsis seedlings induced by obstacle-touching stimulus. Science, 250, 274-276.

Okada K. and Shimura Y., 1992. Aspects of recent development in mutational studies of plant signaling pathways. Cell, 70, 369-372.

Poethig S., 1987. Clonal analysis of cell lineage patterns in plant development. Amer. J. Bot., 74, 581-594.

Przemeck G., Mattsson J., Hardtke C., Sung Z. R. and Berleth T., 1996. Studies on the role of the Arabidopsis gene MONOPTEROS in vascular development and plant cell axialization. Planta, 200, 229-237.

Reed J. W., Nagpal P., Poole D. S., Furuya M. and Chory J., 1993. Mutations in the gene for the red/far-red light receptor phytochrome B alter cell elngation and physiological responses throughout Arabidopsis development. Plant Cell, 5, 147-157.

Rerie W. G., Feldmann K. A. and Marks M. D., 1994. The GLABRA2 gene encodes a homeodomain protein required for normal trichome development in Arabidopsis. Genes Devel., 8, 1388-1399.

Rost T., Baum S. and Nichol S., 1996. Root apical organization in Arabidopsis thaliana ecotype "WS" and a comment on root cap structure. Plant Soil, 187, 91-95.

Rutherford R. and Masson P. H., 1996. Arabidopsis thaliana sku mutant seedlings show exaggerated surface- 
dependent alteration in root growth vector. Plant Physiol., 111, 987-998.

Scheres B., Wolkenfelt H., Willemsen V., Terlouw M., Lawson E., Dean C. and Weisbeek P., 1994. Embryonic origin of the Arabidopsis primary root and root meristem initials. Development, 120, 2475-2487.

Scheres B., Di Laurenzio L., Willemsen V., Hauser M.-T., Janmaat K., Weisbeek P. and Benfey P. N., 1995. Mutations affecting the radial organisation of the Arabidopsis root display specific defects throughout the embryonic axis. Development, 121, 53-62.

Scheres B., McKhann H., van den Berg C., Willemsen V., Wolkenfelt H., de Vrieze G. and Weisbeek P., 1996. Experimental and genetic analysis of root development in Arabidopsis thaliana. In Plant roots: from cells to systems; Kluwer Dordrecht The Netherlands, in press.

Schiefelbein J. W. and Somerville C., 1990. Genetic control of root hair development in Arabidopsis thaliana. Plant Cell, 2, 235-243.

Schiefelbein J. W., Galway M. E., Masucci J. D. and Ford S., 1993. Pollen tube and root-hair tip growth is disrupted in a mutant of Arabidopsis thaliana. Plant Physiol., 103, 979-985.

Schneider K., Wells B., Dolan L. and Roberts K., 1997. Structural and genetic analysis of epidermal cell differentiation in Arabidopsis primary roots. Development, 124, 1789-1798.

Simmons C., Migliaccio F., Masson P., Caspar T. and Söll D., 1995. A novel root gravitropism mutant of Arabidopsis thaliana exhibiting altered auxin physiology. Physiol. Plant., 93, 790-798.

Steeves T. A. and Sussex I. M., 1989. Patterns in plant development. Cambridge University Press, Cambridge.

Sulston J. and Horvitz H., 1977. Postembryonic cell lineages of the nematode Caenorhabditis elegans. Dev. Biol., 56. 110-156.
Sulston J. and White J., 1980. Regulation and cell autonomy during postembryonic development of Caenorhabditis elegans. Dev. Biol., 78, 577-597.

Sundaresan V., Springer P., Volpe T., Haward S., Jones J. D .G., Dean C., Ma H. and Martiensen R., 1995. Patterns of gene action in plant development revealed by enhancer trap and gene trap transposable elements. Genes Dev., 9, 1797-1810.

Takahashi T., Gasch A., Nishizawa, N. and Chua N.-H., 1995. The DIMINUTO gene of Arabidopsis is involved in regulating cell elongation. Gene's Dev., 9, 97-107.

Tanimoto M., Roberts K. and Dolan L., 1995. Ethylene is a positive regulator of root hair development in Arabidopsis thaliana. Plant J., 8, 943-943.

Topping J.F. and Lindsey K., 1997. Promoter trap markers differentiate structural and positional components of polar development in Arabidopsis. Plant Cell, in press.

Torrey J.G., 1950. The induction of lateral roots by indoleacetic acid and root decapitation. Am. J. Bot., 37 , 257-264.

Van den Berg C., Willemsen V., Hage W., Weisbeek P. and Scheres B., 1995. Cell fate in the Arabidopsis root meristem determined by directional signalling. Nature, 378, 62-65.

Wang H., Lockwood S. K., Hoeltzel M. F. and Schiefelbein $\mathbf{J}$. W., 1997. The ROOT HAIR DEFECTIVE3 gene encodes an evolutionarily conserved protein with GTP. binding motifs and is required for regulated cell enlargement in Arabidopsis. Genes Dev., 11, 799-811.

Weigel D. and Meyerowitz E. M., 1994. The ABCs of floral homeotic genes. Cell, 78, 203-209.

Wood W., 1991. Evidence from reversal of handedness in $C$. elegans embryos for early cell interactions determining cell fates. Nature, 349, 536-538. 